\title{
Myosins $\mathrm{XI}-\mathrm{K}, \mathrm{XI}-1$, and $\mathrm{XI}-2$ are required for development of pavement cells, trichomes, and stigmatic papillae in Arabidopsis
}

\author{
Eve-Ly Ojangu ${ }^{1 *}$, Krista Tanner ${ }^{1}$, Pille Pata ${ }^{1}$, Kristel Järve ${ }^{1}$, Carola L Holweg ${ }^{2}$, Erkki Truve ${ }^{1}$ and Heiti Paves ${ }^{1}$
}

\begin{abstract}
Background: The positioning and dynamics of vesicles and organelles, and thus the growth of plant cells, is mediated by the acto-myosin system. In Arabidopsis there are 13 class XI myosins which mediate vesicle and organelle transport in different cell types. So far the involvement of five class XI myosins in cell expansion during the shoot and root development has been shown, three of which, $\mathrm{XI}-1, \mathrm{XI}-2$, and $\mathrm{XI}-\mathrm{K}$, are essential for organelle transport.

Results: Simultaneous depletion of Arabidopsis class XI myosins XI-K, XI-1, and XI-2 in double and triple mutant plants affected the growth of several types of epidermal cells. The size and shape of trichomes, leaf pavement cells and the elongation of the stigmatic papillae of double and triple mutant plants were affected to different extent. Reduced cell size led to significant size reduction of shoot organs in the case of triple mutant, affecting bolt formation, flowering time and fertility. Phenotype analysis revealed that the reduced fertility of triple mutant plants was caused by delayed or insufficient development of pistils.

Conclusions: We conclude that the class $\mathrm{XI}$ myosins $\mathrm{XI}-\mathrm{K}, \mathrm{XI}-1$ and $\mathrm{XI}-2$ have partially redundant roles in the growth of shoot epidermis. Myosin XI-K plays more important role whereas myosins XI- 1 and XI-2 have minor roles in the determination of size and shape of epidermal cells, because the absence of these two myosins is compensated by $\mathrm{XI}$-K. Co-operation between myosins $\mathrm{XI}-\mathrm{K}$ and $\mathrm{XI}-2$ appears to play an important role in these processes.
\end{abstract}

\section{Background}

The size, shape and growth of plant organs are regulated by genetic and environmental factors [1]. There are several excellent systems in Arabidopsis to study epidermal cell development, root hairs, pavement cells, and trichomes are well-studied model systems to investigate the mechanisms of cell growth and morphogenesis [2]. Studies have shown that cytoskeletal dynamics, vesicle transport, small GTPase signaling and endoreduplication all play a role in the development of the specialized shapes of different epidermal cell types. Some mechanisms that determine cell shape and polarity are common between these cell types, while some remain specific to each [3].

\footnotetext{
* Correspondence: eve-ly.ojangu@ttu.ee

${ }^{1}$ Department of Gene Technology, Tallinn University of Technology,

Akadeemia tee 15, 12618 Tallinn, Estonia

Full list of author information is available at the end of the article
}

Myosins are molecular motors that carry cargo along actin filaments. The actomyosin system plays a crucial role in regulating cellular structures and dynamics [4]. Phylogenetic analysis has revealed that the 17 myosin genes present in the Arabidopsis genome fall into two classes: class VIII containing 4 genes and class XI containing 13 genes [5-8]. Class VIII myosins are implicated in new cell wall formation, intercellular transport through plasmodesmata and endocytosis [9-13]. Immunolocalization and co-localization experiments have indicated that class XI myosins are involved in the movement of vesicles and organelles [14-17]. Studies using T-DNA mutant lines, RNA interference or overexpression of dominant-negative myosin forms have confirmed that particular class XI myosins are required for movement of Golgi stacks, mitochondria and peroxisomes [7,18-22]. A novel role in regulation of the actin cytoskeleton and ER dynamics has been shown for class XI myosins [22,23]. In addition, phenotype analysis of T- 
DNA insertional mutants in each of the 13 class XI myosins has shown that only two class XI myosins are important for normal development of specific epidermal cells: XI-K and XI-2 are required for the tip growth of root hairs and XI-K also plays a role in diffuse growth of trichomes $[19,24]$. Since mutants in only two of the 13 class XI myosin genes have a distinct phenotype, it has been proposed that the functions of class XI myosins are partially overlapping $[19,20]$. This hypothesis has been largely proven by phenotype analysis of double, triple and quadruple mutants, which showed that five class XI myosins (XI-1, XI-2, XI-K, XI-B and XI-I) exhibit varying degrees of functional redundancy in Arabidopsis $[20,22]$. Simultaneous inactivation of these myosins in triple and quadruple mutants influenced overall plant growth and fertility, affecting shoot development even more than root development. Triple and quadruple mutant lines exhibited dwarf rosette growth, reduced plant height, late flowering phenotype, reduced fertility and also reduced growth of roots and root hairs. It is now thought that vegetative development of Arabidopsis relies on the four myosins (XI-K, XI-2, XI-1, XI-I) and that organelle transport driven by these myosin motors is required both for polarized growth as well as for diffuse growth of plant cells [22].

Myosins represent only one of many different types of actin binding proteins. Actin binding proteins are specialized to regulate dynamics and organization of the actin cytoskeleton. Mutants of these proteins have a wide range of phenotypes. A common characteristic of these mutants is irregular expansion and shape of trichomes, leaf pavement cells, and epidermal cells of the hypocotyl and root [25-28]. A group of mutants, named distorted, were initially identified based on a distorted or irregular trichome phenotype. These plants carry mutations in genes coding actin polymerization regulating proteins, like components of ARP2/3 [29,30] and SCAR/ WAVE complexes [31-34]. Trichomes of these mutants are smaller, bloated and misshapen due to aberrant expansion of the stalk and branches [29,30,33,35-38]. Two other phenotypically similar mutants, identified as weak distorted mutants are myosin mutant $x i-k$ and the WD40/BEACH domain protein mutant spirrig. The trichome phenotype of spirrig mutants is weaker compared to other distorted mutants and the phenotype of $x i-k$ in turn is weaker than that of spirrig mutants. Partial phenotypic overlap with distorted mutants indicated that XI-K and SPIRRIG could be involved in similar growth processes of certain epidermal cells as are ARP2/ 3 and/or SCAR/WAVE complex proteins [24,39].

To reveal the detailed functions of myosins XI-K, XI-1 and XI-2 in growth and development of epidermal cells we analyzed double and triple T-DNA insertional mutants of these myosins. The results of this current work show that these three myosins contribute to the development of different epidermal cells - not only to the growth of root hairs and leaf pavement cells, but also to the coordinated expansion of trichomes and elongation of the stigmatic papillae. Simultaneous depletion of all three myosins resulted in dwarf growth, delay in bolting and flower development and reduced fertility. Our results indicated that the reduced fertility of triple mutant plants was caused by delayed or insufficient development of floral organs. This manifested in insufficiently developed pistils that were not fully receptive for pollination. Our results also indicate that myosin XI-K plays a more important role in the determination of epidermal cell size and shape than the other two myosins examined.

\section{Results}

Myosins $\mathrm{XI}-1, \mathrm{XI}-2$ and $\mathrm{XI}-\mathrm{K}$ have overlapping roles in regulating shoot size

Double mutant lines $x i-1 / x i-2, x i-1 / x i-k, x i-2 / x i-k$ and triple mutant line $x i-1 / x i-2 / x i-k$ were generated, and the genotype combinations were identified by PCR. Single mutant lines used for crossings were analyzed by RTPCR to confirm the presence or lack of myosin mRNAs

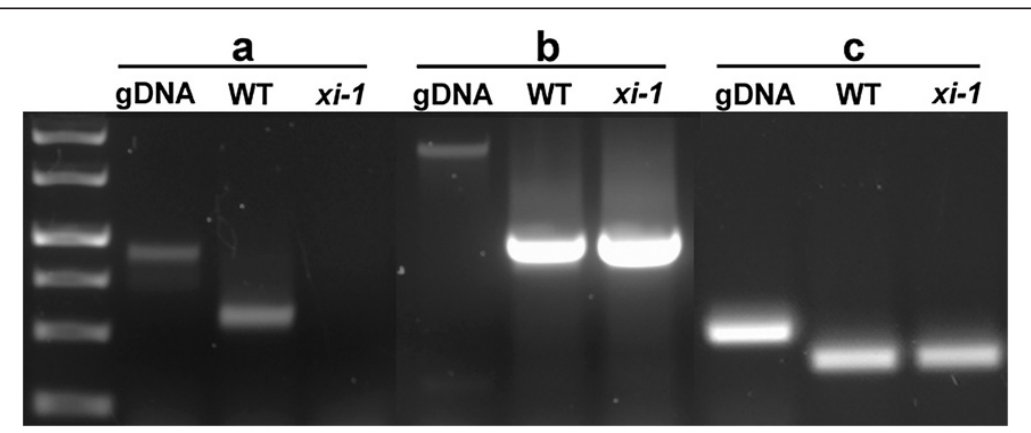

Figure 1 RT-PCR analysis of the XI-1 T-DNA insertional line Salk_022140. Two different primer pairs were used to amplify two regions within the XI-1 mRNA: $\mathbf{a}$ - primers spanning the T-DNA insertion site; $\mathbf{b}$ - primers for downstream region of the T-DNA insertion site; $\mathbf{c}$ - control amplified with GAPB primers. gDNA - genomic DNA; WT - wild type. 
in each mutant. When primers downstream of the TDNA insertion site were used for RT-PCR, the respective myosin transcript was absent in $x i-2$ (data not shown; see [19]), present in $x i-1$ (Figure 1) and present in $x i-k$ (data not shown; see $[19,24]$ ) mutants. When primers spanning the T-DNA insertion site were used, none of the mutant lines produced any transcript (see Figure 1 for $x i-1$ ). It has been shown previously that no XI-K protein is produced in the $x i-k$ mutant, although the corresponding mRNA was present [19]. In $x i-1$ mutant, the T-DNA is inserted into the coding region; thus, we assumed that no functional XI-1 protein can be produced in this single mutant as well as in respective double and triple mutant plants. A schematic diagram shows T-DNA insertions sites for mutant lines $x i-1, x i-2$ and $x i-k$ (see Additional file 1).

To uncover the possible functions of myosins XI-1, $\mathrm{XI}-2$ and XI-K in development of various epidermal cell types, we analyzed the overall phenotype of respective double and triple mutant plants. $x i-2 / x i-k$ double mutants had a slightly decreased rosette size while $x i-1 /$ $x i-2 / x i-k$ triple mutants showed more reduced rosette size (Figure 2A). Rosette size of all single mutants and the double mutants $x i-1 / x i-2$ and $x i-1 / x i-k$ was similar to that of wild type and was not investigated further. Rosettes of $x i-2 / x i-k$ and $x i-1 / x i-2 / x i-k$ were investigated in more detail and both the leaf size as well as the cell area of rosette leaves was measured. Leaf size measurements showed that average length of $x i-2 / x i-k$ leaf blade was similar to wild type and for $x i-1 / x i-2 / x i-k$ it was $21 \%$ $(\mathrm{p}<0.01)$ smaller (Figure 2B; Additional file 2). The average width of the leaf blade of $x i-2 / x i-k$ and $x i-1 / x i-2 /$ $x i-k$ was comparable with wild type. The average length of $x i-2 / x i-k$ and $x i-1 / x i-2 / x i-k$ petioles was $24 \%(\mathrm{p}<0.01)$ and $40 \%(\mathrm{p}<0.01)$ shorter than in wild type, respectively (Figure 2B; Additional file 2). Cell size measurements revealed that pavement cell area of $x i-2 / x i-k$ and $x i-1 /$ $x i-2 / x i-k$ plants was reduced by $17 \%(\mathrm{p}<0.05)$ and $35 \%(\mathrm{p}<0.01)$ and mesophyll cell area by $9 \%$ and $20 \%$, respectively (Figure $2 \mathrm{C}$, Additional file 3 ). In addition, we found that pavement cells of $x i-1 / x i-2 / x i-k$ leaves had slightly less expanded lobes than those of wild type (Figure 2D). Circularity as a quantitative descriptor of cell shape complexity has been used for characterization of several cell types in plants. A perfect circle has the circularity equal to 1.0 and a cell with many deep lobes would have the circularity closer to 0 [40-42]. To characterize the shape of pavement cells, Image-J based circularity value of wild type and $x i-1 / x i-2 / x i-k$ cells of the 5th and 6th rosette leaf was calculated. The average circularity of wild type and $x i-1 / x i-2 / x i-k$ pavement cells was 0.041 and $0.139(\mathrm{p}<0.0001)$, respectively (Figure 2E, Additional file 4), meaning that the pavement cells of the triple mutant are more round.
The results confirmed that myosins XI-1, XI-2 and XI$\mathrm{K}$ have overlapping roles in shoot development, and that myosins $\mathrm{XI}-\mathrm{K}$ and $\mathrm{XI}-2$ are more important in this process than the XI-1.

We also noted that both bolt formation and onset of flowering of $x i-1 / x i-2 / x i-k$ plants was delayed for two weeks on average (Additional file 5). In addition, the flowering time of $x i-2 / x i-k$ plants was occasionally delayed for about a week (data not shown). The average height of the inflorescence shoots of $x i-2 / x i-k$ and $x i-1 /$ $x i-2 / x i-k$ plants was reduced $9 \%$ and $17 \%(\mathrm{p}<0.001)$, respectively, when compared to wild type (Additional file 6). In addition, the growth of root hairs of double and triple mutant plants was decreased in a similar manner as described previously $[20,22]$ (data not shown).

\section{Distorted trichome phenotype of $x i-k$ is amplified in double and triple mutant plants}

We have previously shown that myosin mutant $x i-k$ partially phenocopies the mild trichome phenotype of distorted mutants [24]. Therefore leaf trichomes of myosin double and triple mutant plants were examined. Two parameters were followed to characterize trichomes cell size and shape. For the size analysis, the length of trichome branches and the height of stalk was measured. The branch length and stalk height in $x i-1$ and $x i-2$ was similar to wild type (Figure 3A, Additional file 7). The average length of $x i-k$ trichome branches was $83 \%$ of wild type but the height of the stalk was similar to wild type (Figure 3A, Additional file 7). Size measurements showed that trichomes of $x i-1 / x i-2$ were comparable with wild type. Trichome branch length of $x i-1 / x i-k$ was $79 \%$ of wild type and comparable with $x i-k$. The length of trichome branches of $x i-2 / x i-k$ and $x i-1 / x i-2 / x i-k$ plants was $70 \%(\mathrm{p}<0.001)$ and $40 \%(\mathrm{p}<0.001)$ of wild type, respectively (Figure 3A, Additional file 7). In contrast, trichome stalks of $x i-1 / x i-k$ and $x i-2 / x i-k$ were abnormally elongated compared to wild type. The average height of trichome stalks in $x i-1 / x i-k$, and $x i-2 / x i-k$ were $126 \%(\mathrm{p}<0.001)$ and $143 \%(\mathrm{p}<0.001)$ of wild type, respectively (Figure 3A, Additional file 7 ). The stalk height of $x i-1 / x i-2 / x i-k$ trichomes was similar to wild type. The calculation of the branch and stalk length ratios revealed that in wild type, $x i-1, x i-2, x i-k$ and $x i-1 / x i-2$ the stalk height constituted approximately half of the branch length (ratio values from 2.1 to 2.8; Figure 3B; Additional file 8$)$. In $x i-1 / x i-k$ and $x i-2 / x i-k$, the trichome stalks were abnormally elongated, and the height of trichome stalk constituted 70\% $(\mathrm{p}<0.001)$ and $90 \%$ ( $p<0.001$ ) of branch length, respectively (length ratios between 1.3 and 1.5; Figure 3B; Additional file 8). In the case of triple mutant, the length of trichome branches was decreased dramatically and the average height of trichome stalk was equal or slightly longer than the 

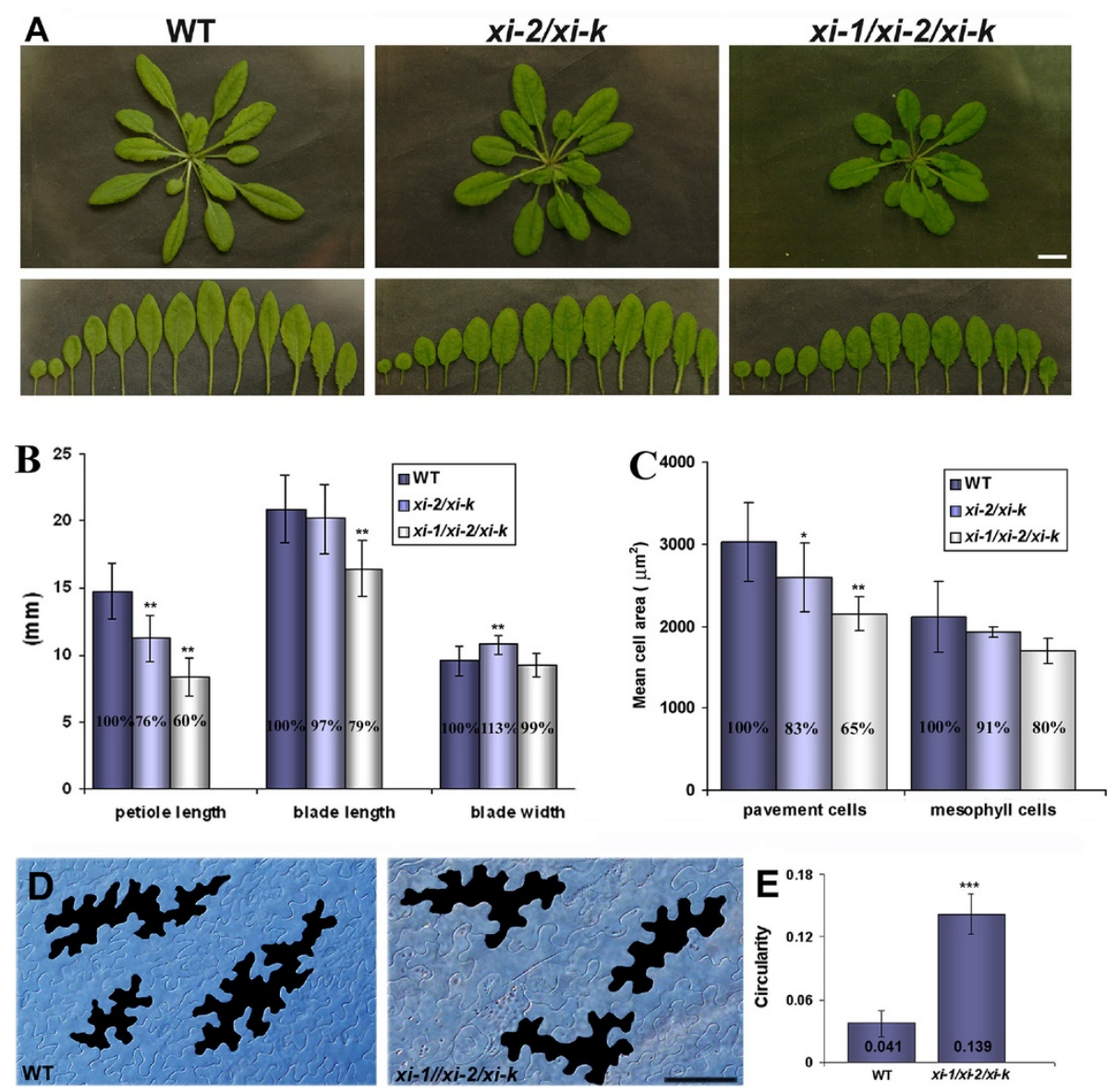

Figure 2 Leaf and cell size. A) Size of the rosette leaves of five-week-old plants. Rosette leaves of $x i-2 / x i-k$ and $x i-1 / x i-2 / x i-k$ in comparison with wild type (WT). Leaves on the lower panel originate from the rosettes on upper panel. Bar $=10 \mathrm{~mm}$. B) Mean size of leaf blades and petioles $( \pm \mathrm{SD})$. The 5 th to 10 th rosette leaves were used for the size measurements. Note shorter petioles and smaller leaf blades of the $x i-2 / x i-k$ and $x i-1 /$ $x i-2 / x i-k$ plants in comparison with WT. Asterisks indicate statistical significance $(* * p<0.01$, Repeated Measures ANOVA with Dunn's Multiple Comparisons Test, $n=18)$. C) Mean cell areas of pavement and mesophyll cells of five-week-old rosette leaves $( \pm S D)$. In the case of $x i-2 / x i-k$ and $x i-1 / x i-2 / x i-k$ the cell area is smaller compared to WT $\left({ }^{*} p<0.05\right.$ and ${ }^{* *} p<0.01$, One-Way ANOVA with Dunnett's Multiple Comparisons Test). D) Shape of pavement cells of leaf abaxial epidermis. Note less extended lobes of the $x i-1 / x i-2 / x i-k$ pavement cells in comparison with WT (black cells on the image). Bar $=50 \mu \mathrm{m}$. E) Circularity values of pavement cells on leaf abaxial epidermis (mean \pm SD). Circularity reflects the ratio of pavement cell area to the perimeter. Cells with values near one are more circular, meaning that $x i-1 / x i-2 / x i-k$ cells have more round morphology than WT cells (*** $p<0.001$, unpaired $t$-test with Welch correction, $n=13-16$ ).

branch length (ratio value below 1, $\mathrm{p}<0.001$; Figure 3B; Additional file 8).

The number of trichomes with irregular shape was quantified by measuring the frequency at which several types of differences from wild type trichome shape occured. The differences we measured were: differences in branch positioning (elongated interbranch zone), individual branch length, stalk height or bended shape of the trichome (Figure 3C). The number of irregular trichomes on leaves of $x i-1, x i-2$ and $x i-1 / x i-2$ plants was similar to wild type (values from $5 \%$ to $8 \%$ ). In $x i-k$ plants, $22 \%$ of leaf trichomes exhibited an irregular phenotype. Trichomes on the leaves of the double mutants $x i-1 / x i-k, x i-2 / x i-k$ and the triple mutant $x i-1 /$ $x i-2 / x i-k$ were more irregular than those on the single mutant $x i-k$. Specifically, in the double mutant $x i-1 / x i-k$; approximately $38 \%$ of leaf trichomes showed irregular phenotype compared to $x i-k$. Very characteristic for $x i-$ $1 / x i-k$ was the appearance of trichomes with abnormally elongated stalks, a phenotype not found in the single $x i$ $k$ mutant (Figure 3C). Trichome phenotype of $x i-k$ was more severe in $x i-2 / x i-k$ and $x i-1 / x i-2 / x i-k$ plants, where $56 \%$ and $90 \%$ of trichomes were irregular and frequently exhibited both abnormally elongated stalks as well as abnormally elongated single branches (sword-shaped trichomes) (Figure 3C, Additional files 7 and 8). In the case of $x i-1 / x i-k, x i-2 / x i-k$ and $x i-1 / x i-2 / x i-k$ plants, the bent shape of trichomes was more frequent than in $x i-k$. 


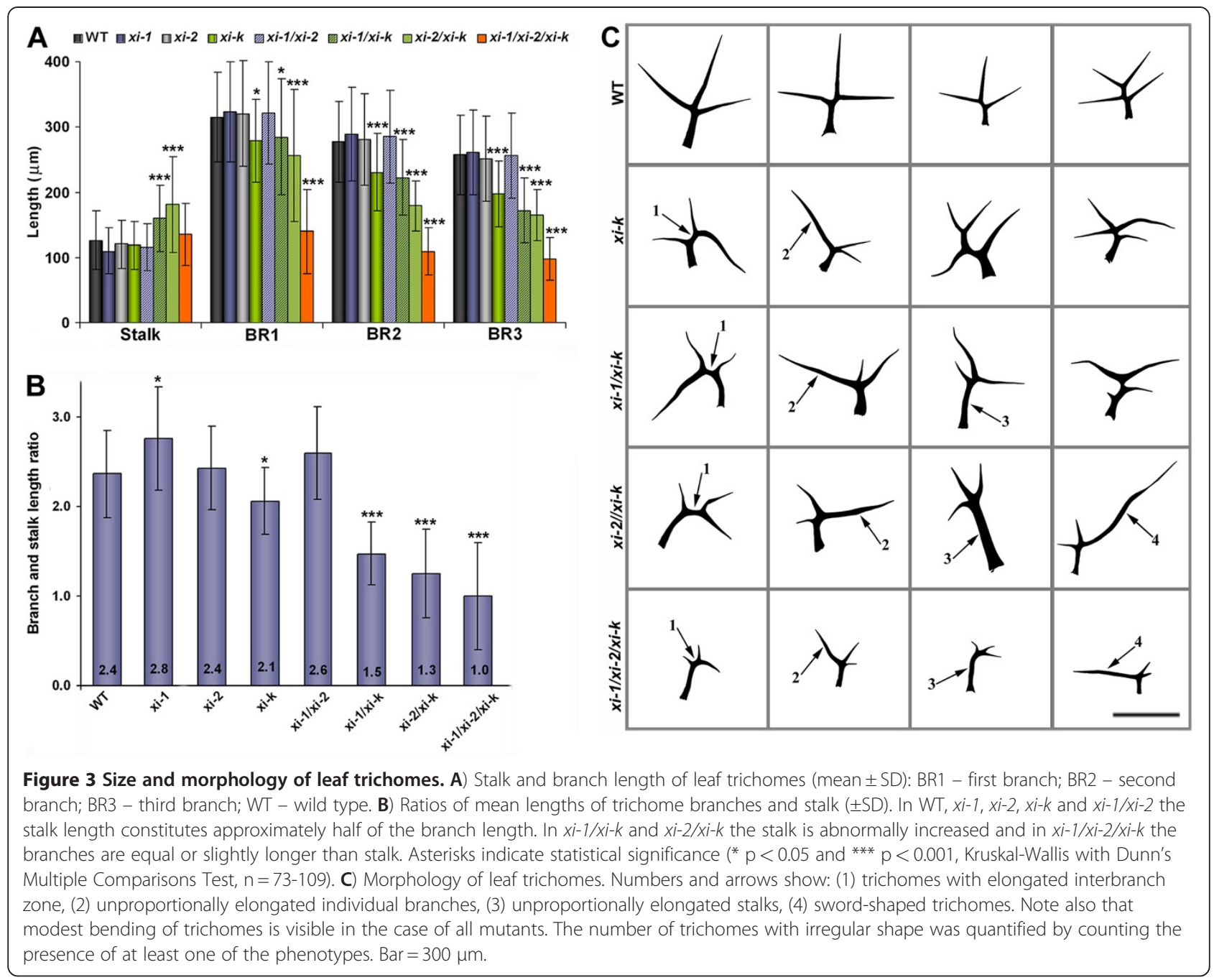

We used scanning electron microscopy to monitor stalk and branch expansion defects during trichome development. Trichome development is divided into six stages based on morphological features. Stage 4 and 5 trichomes were investigated because branches are formed in stage 4 and rapid branch elongation begins in stage $5[35,43]$. We did not detect significant differences between stage 4 trichomes of double mutant, triple mutant and wild type plants. Differences between wild type and mutant trichomes, irregular elongation and modest bending of stalk and branches, were clear in late stage 5 or stage 6 trichomes of $x i-1 / x i-k, x i-2 / x i-k$, and $x i-1 / x i-2 /$ $x i-k$ plants (Figure 4A-H).

The phenotype of double mutants $x i-1 / x i-k, x i-2 / x i-k$ and triple mutant $x i-1 / x i-2 / x i-k$ all show more severe mutant phenotypes than any single mutant, suggesting that all three myosins participate in elongation of trichome stalks and branches. Among these mutants $x i-1 / x i-k$ had the weakest and $x i-1 / x i-2 / x i-k$ had the strongest phenotype. These results indicate that myosin XI-K contributes more significantly than XI-1 and XI-2 to the trichome development because the absence of both myosins can be compensated by XI-K. Myosin XI-2 in turn plays a more important role in the trichome expansion than XI-1, as the phenotype of $x i-2 / x i-k$ was stronger than that of $x i-1 / x i-k$.

\section{Simultaneous depletion of myosins $\mathrm{XI}-1, \mathrm{XI}-2$ and $\mathrm{XI}-\mathrm{K}$ influences the shape of trichome nuclei}

Wild type trichomes undergo approximately four rounds of endoreduplication during maturation leading to a three to four branched cell with an average DNA content of $32 \mathrm{C}$ (32 times the DNA content of the haploid genome) [44-47]. It has been found that mutants with smaller trichomes contain less DNA, whereas mutants with increased cell size were found to have additional endoreduplication rounds [46]. To test whether the smaller size of myosin mutant trichomes could be related to the ploidy level, we quantified the nuclear DNA of fully mature trichomes on 14 days old plants using Hoechst staining. Confocal scanning fluorescence 


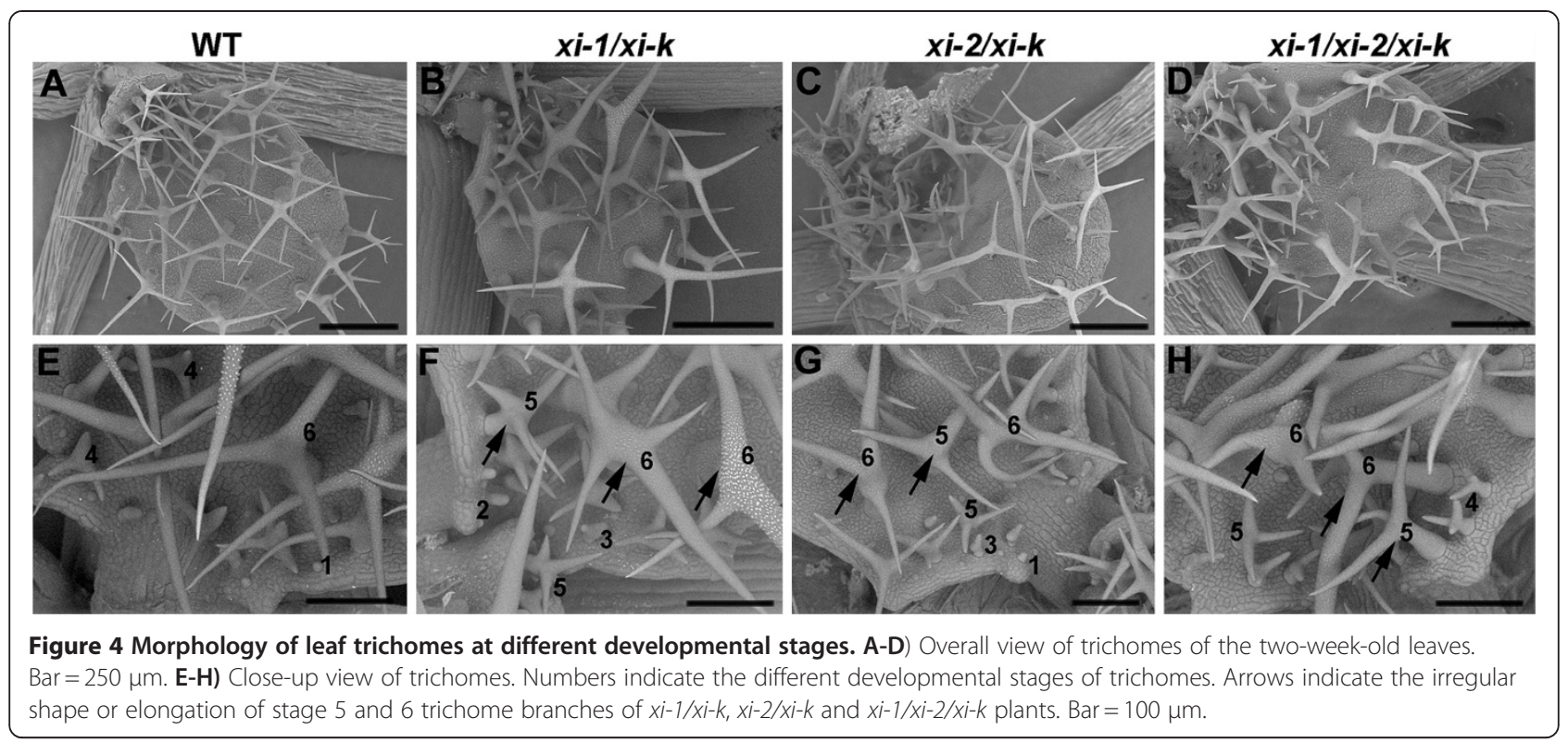

microscopy measurements showed that the ploidy level of the single, double and triple mutant trichomes was similar to wild type, average DNA content being $32 \mathrm{C}$ (data not shown), suggesting that trichomes of these mutants undergo four successive endoreplication cycles during maturation, as in wild type.

Although we did not detect differences in ploidy level, we found that the nuclei of mutant trichomes exhibited a different shape compared to wild type. Trichomes of all single mutants and double mutants $x i-1 / x i-2$ and $x i-1 / x i-k$ had spherically shaped nuclei, similar to wild type. Trichomes of $x i-2 / x i-k$ and $x i-1 / x i-2 / x i-k$ frequently had abnormally elongated nuclei (Figure 5A). Quantification analysis revealed that the average sphericity of wild type trichome nuclei was 0.65 and that of $x i-1, x i-2, x i-k, x i-1 /$ $x i-2$ and $x i-1 / x i-k$ nuclei was between 0.58 and 0.62 (Figure Inter/InternalRef $>$, Additional file 9). The average sphericity of $x i-2 / x i-k$ and $x i-1 / x i-2 / x i-k$ trichomes was $0.52(\mathrm{p}<0.001)$ and $0.60(\mathrm{p}<0.001)$, respectively (Figure $5 \mathrm{~B}$, Additional file 9). Taken together, nuclei of wild type trichomes had the most circular shape and nuclei of double mutant $x i-2 / x i-k$ had the most elongated shape, indicating that co-operation between myosin XI-K and XI-2 is necessary for normal nuclear morphology in trichomes. Since both the irregular trichome shape and the sphericity of nucleus were most dramatically expressed in $x i-2 / x i-k$ background, a correlation analysis between these phenotypic features in $x i-2 / x i-k$ was performed. The calculated Pearson's correlation coefficient $r=-0.7120(\mathrm{p}<0.0001$; $\mathrm{n}=32$ ) shows that smaller nuclear sphericity values (i.e. nucleus is elongated) are correlated with mutant trichome phenotype (Additional file 10).

\section{Simultaneous depletion of myosins XI-1, XI-2 and XI-K} influences the growth of floral organs and fertility

To assess the fertility of the analyzed double and triple mutant lines, the number and length of the siliques per plant was measured and the number of seeds per silique was counted. Fertility of single and double mutant lines was comparable to wild type and was therefore not investigated further. For $x i-1 / x i-2 / x i-k$, variations in the number of normally and abnormally developed siliques were significant (siliques with length from 4 to $10 \mathrm{~mm}$ were assessed as abnormal). As an average, $x i-1 / x i-2 / x i-k$ plants had up to $60 \%(\mathrm{p}<0.001)$ of abnormally developed siliques on main stem, when compared to wild type (Figure 6, Additional file 11).

Moreover, after onset of flowering, up to 60\% (p $<0.001$ ) of flowers emerged on the primary shoot of $x i$ $1 / x i-2 / x i-k$ plants remained mostly seedless because the pistils remained unpollinated or were poorly pollinated (Figure 7A-B, Additional file 11). The average length of these siliques was $6.5 \mathrm{~mm}(\mathrm{p}<0.001)$ containing an average of only two $(\mathrm{p}<0.001)$ fertilized ovules (Figure 7A-B; Additional file 12). This process continued approximately two to three weeks after bolting. About three weeks after bolting, there was a "switch" and plants started to produce siliques only slightly underdeveloped or normal in size with average length $12.9 \mathrm{~mm}$ (Figure 7A-B, Additional file 12). These siliques contained up to $28 \%(\mathrm{p}<0.0001)$ of unfertilized ovules (Figure 7C, Additional file 12). The number of unpollinated pistils, underdeveloped and normal siliques varied to a great extent between the $x i-1 / x i-2 / x i-k$ plants. These variations in silique size were prevalent on primary shoots and less on axillary shoots of $x i-1 / x i-2 / x i-k$ 

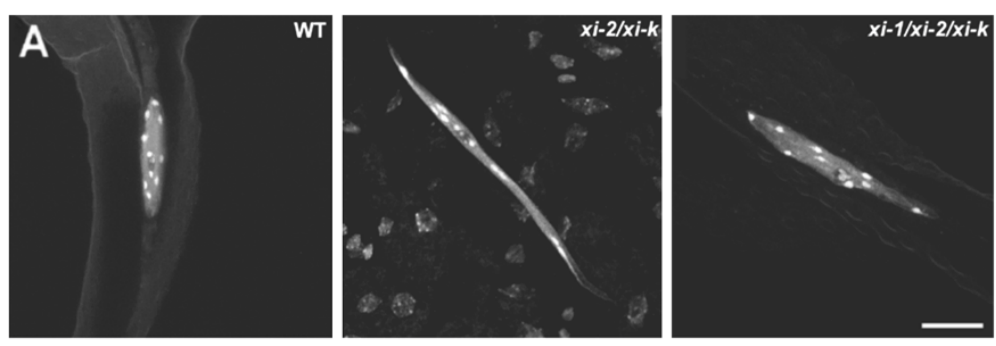

B

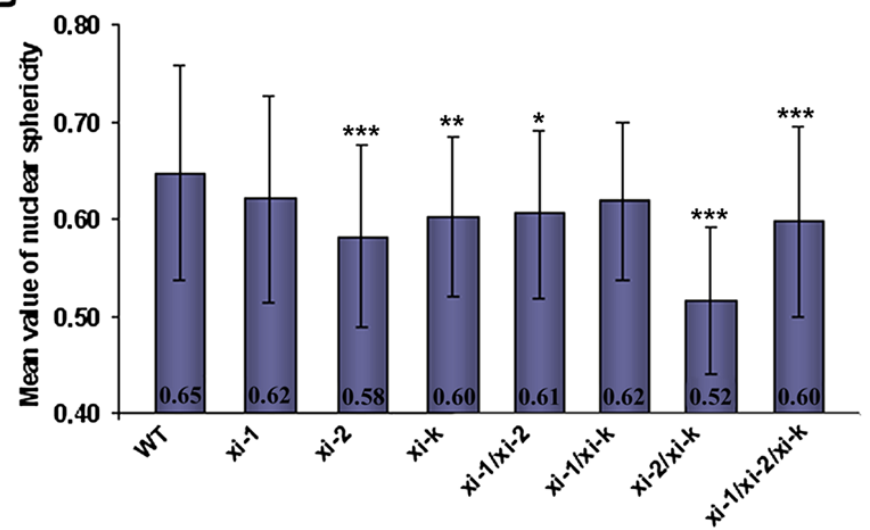

Figure $\mathbf{5}$ Shape of leaf trichome nuclei. A) Hoechst stained nuclei of two-week-old leaf trichomes. Abnormally elongated nuclei of $x i-2 / x i-k$ and $x i-1 / x i-2 / x i-k$ trichomes are shown. Bar $=15 \mu \mathrm{m}$. B) Sphericity of trichome nuclei (mean \pm SD). Sphericity is the ratio of the volume of a nucleus to the surface area of the nucleus, which is the smallest in xi-2/xi-k mutants. Asterisks indicate statistical significance $\left(^{*} p<0.05,{ }^{* *} p<0.01\right.$, and ${ }^{* * *}$ $p<0.001$, Kruskal-Wallis with Dunn's Multiple Comparisons Test, $n=55-157)$.

plants. In wild type, occasionally the first two flowers on the inflorescence remained seedless and the number of underdeveloped siliques was up to $5 \%$ (Additional file 12).

Next, anthers and pistils were examined to identify whether the decreased fertility of triple mutant was caused by defects in male or female reproductive organs. For this, Alexander's staining of pollen, in vitro growth
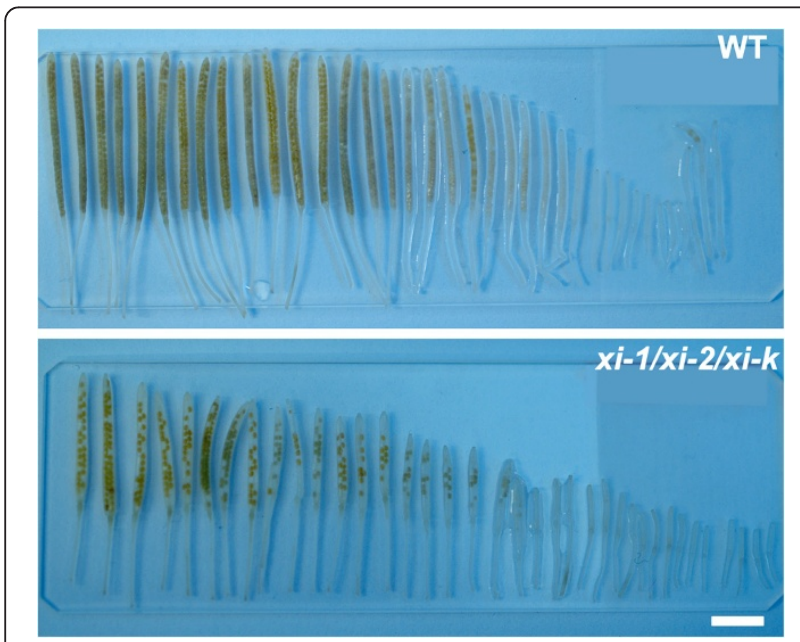

Figure 6 Length of siliques of the primary shoot. $\ln x i-1 / x i-2 / x i-k$, siliques are significantly shorter, containing much less seeds than those in wild type (WT). Bar $=5 \mathrm{~mm}$. assays and aniline blue staining of pollen tubes was performed. Alexander's staining showed that the viability of $x i-1 / x i-2 / x i-k$ pollen grains was similar to wild type (Additional file 13). Using in vitro pollen tube growth assay we could not detect differences between triple mutant and wild type pollen tube growth (data not shown). These results indicated that the decreased fertility of $x i$ $1 / x i-2 / x i-k$ triple mutant plants was not dependent on pollen viability or on the ability of the pollen to form a pollen tube.

Cross-pollination of wild type and $x i-1 / x i-2 / x i-k$ pistils was performed. Aniline blue staining of pollinated pistils demonstrated that when wild type pistils were pollinated with $x i-1 / x i-2 / x i-k$ pollens (WT/triple), the growth of pollen tubes in pistils was similar as in self-pollinated wild type (Figure 8 ). WT/triple siliques contained only 2-5\% unfertilized ovules counted 9 days after pollination. Inversely, when $x i-1 / x i-2 / x i-k$ pistils were pollinated with wild type pollen (triple/WT), pistils developed very heterogeneously. In some cases, the fertilization was normal, but often wild type pollen grains could not attach effectively to the surfaces of $x i-1 / x i-2 / x i-k$ stigmas and form pollen tubes (Figure 8). As a result, triple/WT pistils often remained poorly pollinated, no siliques or shorter siliques were formed and a variable amount of ovules (12-53\%) in shorter siliques remained unfertilized. We observed a similar phenotype both in cross- 

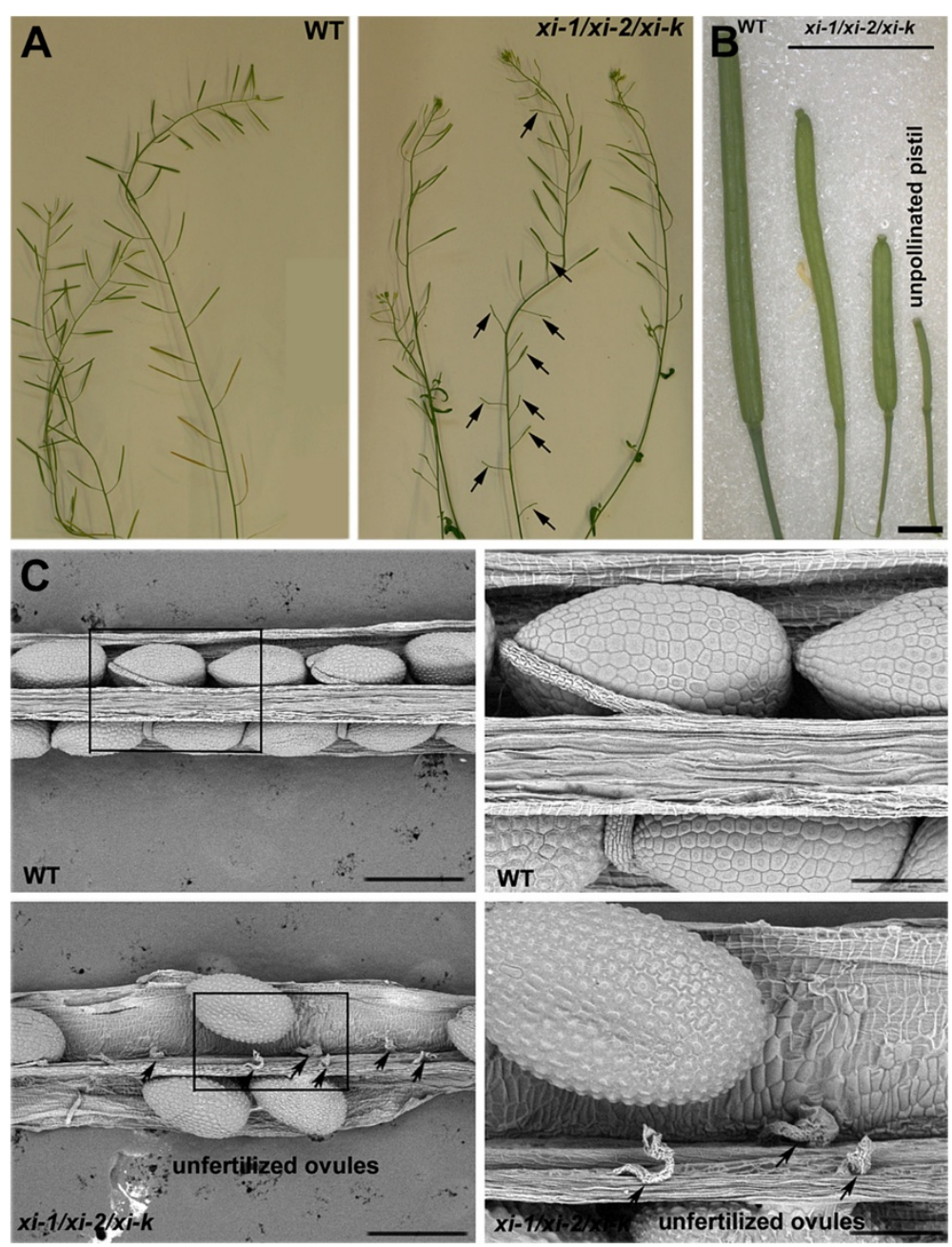

Figure 7 Silique size and seed development. A) Shoots of the eight-week-old plants. Arrows indicate the unpollinated pistils on the primary stem of $x i-1 / x i-2 / x i-k$. B) Representative wild type (WT) and $x i-1 / x i-2 / x i-k$ siliques are shown. Note the heterogenous development of triple mutant siliques on the main stem. Bar $=2 \mathrm{~mm}$. C) Scanning electron micrographs of developing seeds in manually opened siliques. Arrows point to the unfertilized ovules in $x i-1 / x i-2 / x i-k$ siliques. Left panel, bar $=500 \mu \mathrm{m}$; right panel, bar $=150 \mu \mathrm{m}$.

pollinated triple/WT as well as in self-pollinated $x i-1 /$ $x i-2 / x i-k$ pistils (Additional file 14). Reciprocal crosses between the wild type and triple mutant $x i-1 / x i-2 / x i-k$ revealed that the reduced fertility of triple mutant is female reproductive tract specific.

Making reciprocal crosses it seemed that floral organs of $x i-1 / x i-2 / x i-k$ are significantly smaller than those of wild type and the size and architecture of flowers was therefore examined in more detail (Figure 9A). Indeed, measurements of floral organs showed that $x i-1 / x i-2 / x i-k$ flowers were smaller compared to the wild type (Figure 9B, Additional file 15). The length of peduncles, sepals and petals of $x i-1 / x i-$ $2 / x i-k$ flowers was $88 \%, 88 \%(\mathrm{p}<0.01)$ and $83 \%$ $(\mathrm{p}<0.001)$ of wild type, respectively. The length of $x i$ $1 / x i-2 / x i-k$ flower buds was only $66 \%(\mathrm{p}<0.001)$ of wild type (Figure 9B, Additional file 15).
Next, the architecture of the triple mutant and wild type pistils was studied using scanning electron microscopy. Twenty stages of Arabidopsis flower development have been distinguished [41]. Floral buds just before pollination (stage 12) and opened flowers (stage 13 or 14) were examined because wild type pistils of these developmental stages are mature and receptive to pollination. We observed that the elongation of stigmatic papillae of stage $12 x i-1 / x i-2 / x i-k$ buds was delayed, remaining on the level of stage 10 or 11 stigmas (Figure 10A). In stage 13 and 14 flowers the development of $x i-1 / x i-2 / x i-k$ stigmatic papillae varied from normal to stunted. We noticed that in some cases also $x i-1 / x i-2 / x i-k$ pistil itself did not develop to the wild type level even during later stages of development (Figure 10B).

We suggest that the insufficient development of stigmatic papillae, which renders the stigma not fully 


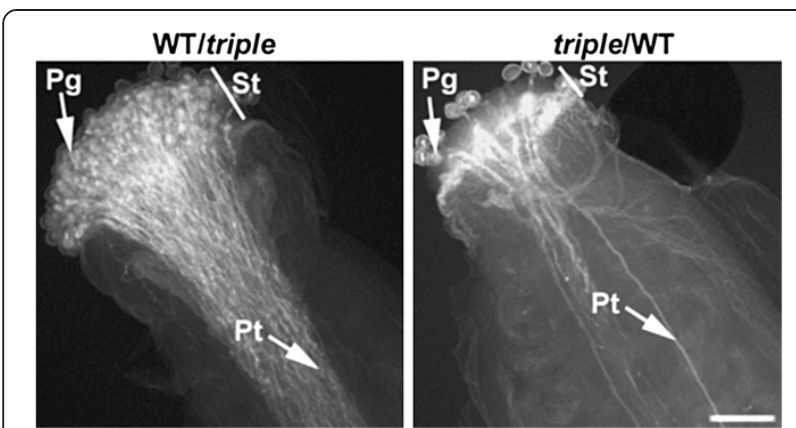

Figure 8 Development of pollen tubes. Pollen tube growth was followed in cross-pollinated pistils: WT/triple - wild type (WT) pistil was pollinated with $x i-1 / x i-2 / x i-k$; triple/WT $-x i-1 / x i-2 / x i-k$ pistil was pollinated with WT. Note the number of pollen grains attached to the stigmas and the number of pollen tubes formed. In the case of triple/WT, WT pollen grains were not able to attach effectively on the surface of $x i-1 / x i-2 / x i-k$ stigma and only few pollen tubes were formed. Aniline blue staining of pollen tubes was performed 12 hours after hand-pollination. Pg - pollen grains, St - stigma, Pt pollen tubes. Bar $=50 \mu \mathrm{m}$.

receptive (mature) for pollination, is the main reason for the reduced fertility of $x i-1 / x i-2 / x i-k$ triple mutant plants. These results indicate that myosins XI-1, XI-2 and XI-K together are needed for normal development of floral organs.

\section{Discussion}

Characterization of double and triple mutant plants revealed that myosins XI-K, XI-1, and XI-2 have redundant functions not only in development of root hairs and shoots $[19,20,22]$ but also in expansion of trichomes, lobe extension of pavement cells, and in elongation of stigmatic papillae. Our results showed that simultaneous depletion of these three myosins affects several types of epidermal cells thereby influencing the growth and size of leaves, inflorescences, floral organs and the fertility of the plant. Differences between most phenotypic features (dwarf growth, decreased cell size, delayed flowering time and reduced fertility) between triple mutant $x i-1 /$ $x i-2 / x i-k$ and wild type, described in this work are similar and comparable with results published by Peremyslov and coworkers [22], and here we add several new characteristics (disorders in the development of pavement cell lobes, trichome stalk and branches and stigmatic papillae). Results concerning rosette size, plant height and fertility of the double mutants $x i-1 / x i-k$ and $x i-2 / x i-k$ are inconsistent with previously published data [20]: we show here that the rosette size and shoot height of the $x i-1 / x i-k$ plants are similar to the wild type, and on the contrary, the rosette size and shoot height of $x i-2 / x i-k$ plants are decreased compared to the wild type. Thus, the mutant phenotype (rosette size, shoot height, onset of flowering, and size and shape of trichomes) of $x i-2 /$ $x i-k$ plants is always stronger than that of $x i-1 / x i-k$ plants and the phenotype of $x i-1 / x i-2 / x i-k$ triple mutant plants is always stronger than that of $x i-2 / x i-k$. Double and triple mutant lines used in this work were different than those described previously [20,22]: different T-DNA insertional lines of the xi-1 (Salk_022140) and $x i-2$ (Sail_632_D12) but the same for $x i-k$ (Salk_067972) were used by us to generate double and triple mutant lines. It is possible that the inconsistency of the shoot phenotype of double mutants can be explained by use of different T-DNA insertional lines for generating double and triple mutant lines. Other aspects like differences in laboratory conditions can cause these differences as well.

The size of plant leaves is determined by a combination of cell number, cell size and intercellular space (reviewed in [48]). Experiments with mericlinal Nicotiana chimeras and Arabidopsis brassinosteroid receptor mutants have shown that the leaf epidermis has a crucial role in regulating leaf size through influencing mesophyll cell number and cell size [48-50]. We show that double mutant $x i-2 / x i-k$ and triple mutant $x i-1 / x i-2 / x i-k$ have smaller and less lobed epidermal cells than wild type, and in addition, these leaves are smaller than wild type. Thus, although the primary effect of the depletion of myosins XI-K, XI-1, and XI-2 in the leaf blade may be on epidermal cell size and shape, this ultimately causes smaller leaves, especially in the triple mutant.

Proper organisation of the actin cytoskeleton is important in coordinating directed expansion of trichome branches and, as has been shown for several distorted group mutants $[26,27,35,51]$. The myosin XI-K mutant phenocopies mild trichome phenotype similar to the distorted group mutants [24]. However, the irregular trichome phenotype has not been found in the rest of the single mutants of class XI myosin genes. Our characterization of the double and triple mutant plants revealed, however, that myosins XI-1, XI-2 and XI-K have redundant functions in the elongation of trichome stalks and branches. Our results indicated that myosin $\mathrm{XI}-\mathrm{K}$ has a leading role and XI-1 and XI-2 have minor roles in trichome development, whereas myosin XI-2 contributes to the trichome expansion more than XI-1.

We found also that the irregular size of myosin double and triple mutant trichomes was independent of endoreduplication events. This is also the case in distorted mutants [52], which define genes coding actin polymerization regulating proteins, like components of ARP2/3 [29,30] and SCAR/WAVE complexes [31-34]. Although the ploidy level of mutant trichomes did not change, we found that nuclear morphology was markedly affected in double mutant $x i-2 / x i-k$ trichomes. The abnormally elongated shape of $x i-2 / x i-k$ nuclei correlated with the mutant trichome phenotype. It is known that 

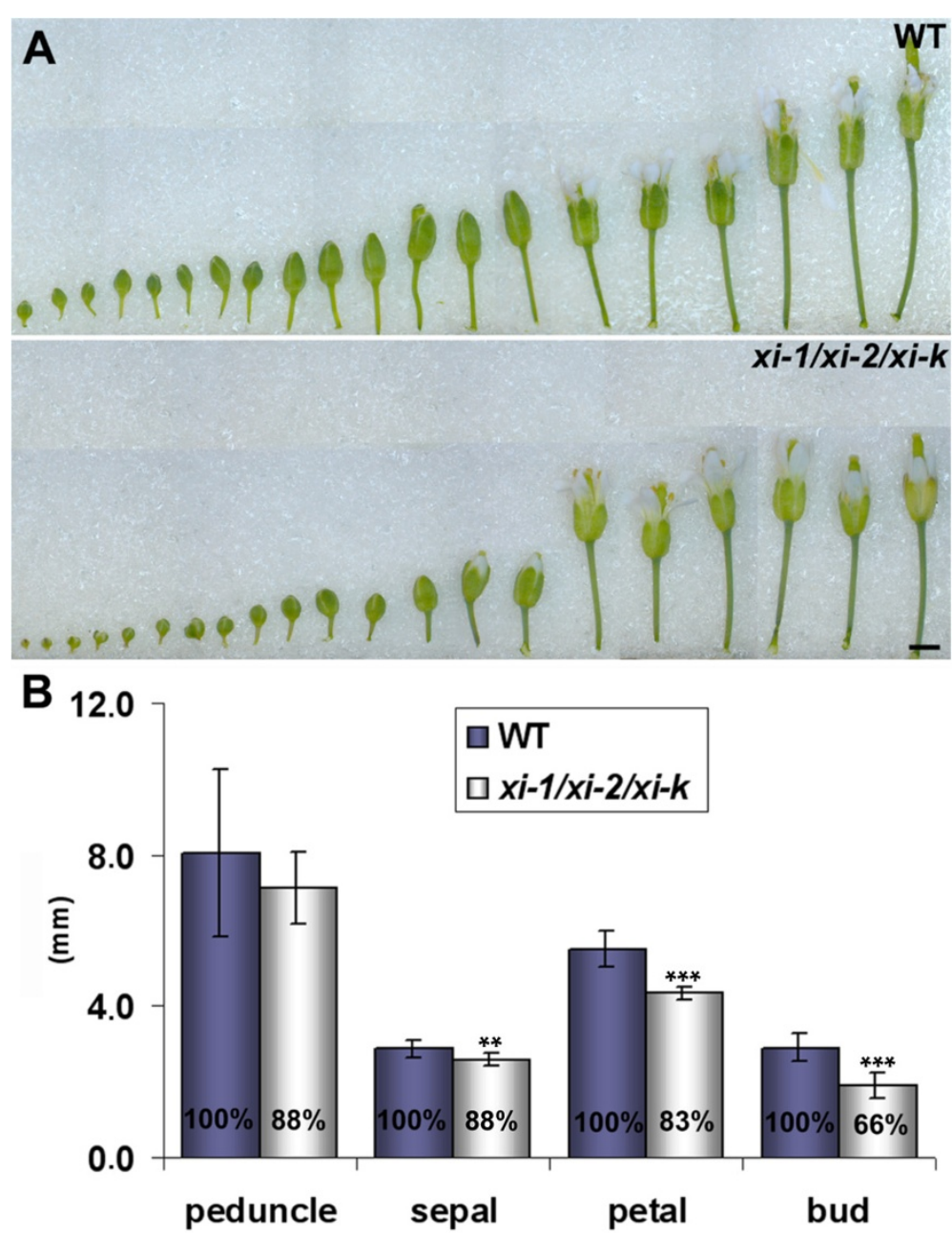

Figure 9 Size of floral organs. A) Developmental stages of flowers from inflorescence of the primary shoot are shown. Note the smaller size of $x i-1 / x i-2 / x i-k$ flowers and flower buds. Bar $=1 \mathrm{~mm}$. B) Mean length of peduncles, sepals, petals and flower buds ( \pm SD). Opened flowers and flower buds of the inflorescences (from main stems) were selected for measurements. The average size of floral organs of $x i-1 / x i-2 / x i-k$ is smaller than in wild type (WT). Asterisks indicate statistical significance $\left({ }^{*} p<0.05\right.$, ** $p<0.01$, and ${ }^{* * *} p<0.001$, unpaired $t$-test with Welch correction, $n=6$-12).

nuclear dynamics and morphology occurs in a cell specific manner and is influenced by cell shape and nuclear DNA content [53]. In plant cells the nucleus is positioned within a basket of dense actin filaments connected to the transvacuolar strands and cortical cytoskeleton [54-56]. Recently it has been shown that simultaneous depletion of myosins XI-1, XI-2 and XI-K caused defects in organization of actin filaments in root hairs and in the cells of leaf midvein epidermis [22]. Moreover, Ueda et al. [23] demonstrated that myosin $\mathrm{XI}-\mathrm{K}$ in co-operation with myosin XI-2 is involved in organizing actin bundles and ER network in epidermal cells of cotyledonary petioles. In addition, transient expression in onion cells showed that GFP-fused headneck domain of XI-2 had an increased fluorescence signal specifically near the nucleus [57]. Taking this into consideration, it is very likely that the organization of actin filaments is affected in the trichomes of $x i-1 / x i-k$, $x i-2 / x i-k$ and $x i-1 / x i-2 / x i-k$ plants. It remains to be resolved how myosins XI-K and XI-2 regulate the organization of the nucleus-associated actin bundles, and thus nuclear shape, during trichome development.

Mutations in genes coding various actin related proteins in plants lead to defects in actin filament organization. For example, the organization of cortical actin filaments in the majority of distorted mutants is affected $[32-34,52,58]$. Comparing the phenotypes of myosin double and triple mutant plants and those of group distorted mutants revealed apparent similarity in the trichome phenotype of the $x i-1 / x i-2 / x i-k$ with pirogi and $x i-2 / x i-k$ with spirrig plants $[31,39]$. It should be noted that the overall phenotype severity of $x i-2 / x i-k$ and $x i-1 /$ $x i-2 / x i-k$ plants was weaker than those of pirogi and spirrig mutants. For example, gaps between adjacent cells in 


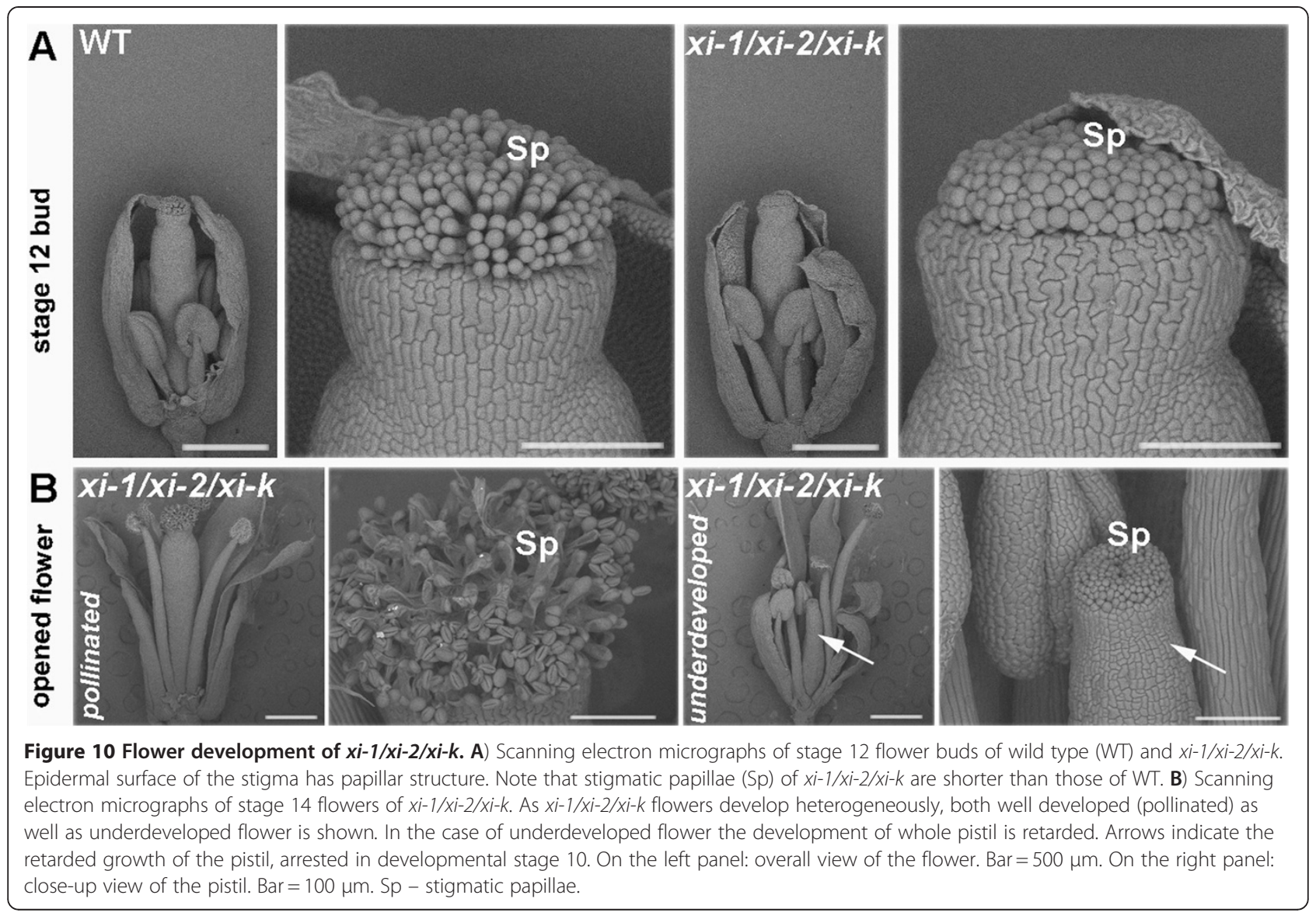

cotyledons and hypocotyls, typical for distorted mutants, were not apparent in the analysed myosin mutants. On the other hand, typical characteristics for $x i-1 / x i-k, x i-2 /$ $x i-\mathrm{k}$ and $x i-1 / x i-2 / x i-k$ trichomes like abnormally elongated trichome stalks have not been reported in distorted mutants. The phenotypic similarity between myosin mutants and distorted mutants also suggests, that the organization of actin filaments could be affected in trichomes of $x i-1 / x i-k, x i-2 / x i-k$ and $x i-1 / x i-2 / x i-k$.

Changes in branch morphology during stage 4 of trichome development are obvious indicators of aberrant actin function in distorted mutants [32-34]. In myosin double and triple mutant plants the irregular trichome phenotype became apparent in late stage 5 or stage 6 trichomes. This reveals that class XI myosins are required for the trichome development during later stages of morphogenesis: during rapid growth of trichome branches or during trichome maturation, when the cell wall thickens and becomes covered with papillae.

Pavement cells of the triple mutant $x i-1 / x i-2 / x i-k$ had less extended lobes. It is known, that the shape of pavement cells and the extension of lobes, depends also on the microfilament dynamics and that most of the distorted mutants display less lobed morphology of pavement cells $[3,34,59]$. Relying on the phenotypic overlap it is tempting to speculate that the functions of myosins XI-K, XI-2 and perhaps of XI-1 may be related to the mechanisms controlled by ARP $2 / 3$ or SCAR/WAVE proteins/complexes.

Reproduction in Arabidopsis is dependent on interactions between pollen grains and papillar cells on the surface of the stigma [60]. The stigma is an epidermal structure composed of papillae, i.e. bulbous elongated cells. In the mature pistil the papillae are properly extended and form elongated cells receptive to the recognition, attachment and germination of pollen grains [61,62]. It has been shown that fewer pollen grains can adhere to immature stigmas and germinate. Immature stigmas are able to promote pollen tube growth to some extent, but the immature pistils are often unable to guide pollen tubes to the ovules $[60,62,63]$. Our current results indicated that the triple mutant $x i-1 / x i-2 / x i-k$ has major deviations in the effectiveness of fertilization. We showed that the reduced fertility of $x i-1 / x i-2 / x i-k$ was caused by delayed or insufficient development of the stigmatic papillae, making pistils less receptive for pollination. This indicates that class XI myosins are required for proper development of Arabidopsis pistils and therefore for fertilization.

Apical-basal patterning of Arabidopsis gynoecium is auxin dependent, and crosstalk between the actin 
cytoskeleton and auxin signaling is well known [64-66]. There are little data available concerning the actin cytoskeleton during pistil development. It has been shown that actin filaments of stigmatic papillae of selfincompatible Brassica rapa are differentially organized before and after pollination and that these changes in actin dynamics are associated with pollen hydration and germination [67]. We suggest, that the class XI myosins in the stigmatic papillae may fulfill a similar role as in other tip growing cell types $[19,20,24]$.

In Arabidopsis not only stigmatic papillae, but also other epidermal cell types like part of the transmitting tract and the integument of the ovules have the same developmental origin, the meristematic epidermal L1 layer [61]. We do not exclude that defects in these cells may also influence the fertility of the $x i-1 / x i-2 / x i-k$, as the flowers of triple mutant were smaller than those of wild type and occasionally exhibited retarded growth with completely underdeveloped pistils. Our results indicate that all three myosins (XI-K, XI-2, XI-1) together are required for normal development of Arabidopsis shoots and floral organs.

\section{Conclusion}

We conclude that (1) myosins XI-1, XI-2 and XI-K have partially redundant roles in the growth of different epidermal cells (pavement cells, trichomes, stigmatic papillae), (2) myosin XI-K has more important role and myosins XI-1 and XI-2 have minor roles in these growth processes, (3) cooperation between myosins XI-K and XI-2 appears to be important for maintaining normal growth of epidermal cells and thus the size of plant organs. We conclude that the decreased size and delayed or insufficient development of floral organs affects the fertility of myosin mutants.

\section{Methods}

Plant material and growth conditions

Arabidopsis thaliana (ecotype Columbia-0) seeds of $x i-1$ (Salk_022140; At1g17580), xi-2 (Sail_632_D12; At5g43900) and $x i-k$ (Salk_067972; At5g20490) T-DNA mutant lines were obtained from the Nottingham Arabidopsis Stock Centre [68]. Homozygous single mutant lines of $x i-k$ (Salk_067972; previously known by allele name XIk-2) and $x i-2$ (Sail_632_D12) have been described earlier [19,24]. Homozygous single mutant lines were used to generate the double mutant lines $x i-1 / x i-2, x i-1 / x i-k, x i-2 / x i-k$ and triple mutant line $x i-1 / x i-2 / x i-k$. Homozygous plants of the double and triple mutant were identified by two PCRs. In the first PCR, a pair of gene-specific primers designed to anneal on either side of the T-DNA insertion were used, which in case of homozygosity does not produce a band of the predicted size. In the subsequent PCR, the T-DNA border specific primer and primers of the first PCR were used. To confirm the location of the T-DNA insertion in the respective myosin gene, the PCR products were sequenced. Double and triple mutant lines used in this work were partially different than those described previously [20,22]: different TDNA insertional lines of the $x i-1$ and $x i-2$ were used to generate double and triple mutant plants.

Seeds from single, double and triple mutant lines were harvested from plants of the same age and stored at least three weeks in the dark at $4^{\circ} \mathrm{C}$. Cold stratified seeds were soaked in water at $4^{\circ} \mathrm{C}$ for $1-4$ days and sowed directly in soil (Biolan OY) containing 50\% (w/v) of vermiculite. Plants were grown in Sanyo growth chambers at $22 \pm 2^{\circ} \mathrm{C}$ and $60 \%$ of relative humidity under long day (16-h light) photoperiod.

\section{RNA isolation and RT-PCR}

RNA was extracted from two-week-old seedlings and DNase I (Ambion) treated as described by Oñate-Sánchez and Vicente-Carbajosa [69]. For first-strand synthesis, RevertAid Premium Reverse Transcriptase (Fermentas) and Random Hexamer Primer mixture (Fermentas) were used according to manufacturer's instructions. Equivalent amounts of cDNA template were used for amplification of fragments of XI-1,XI-2 and XI-K mRNAs. Two pairs of gene specific primers were used for each single mutant: one pair spanning the T-DNA insertion site and the other pair downstream of the insertion site. In all cases constitutively expressed B subunit of chloroplast glyceraldehydes3-phosphate dehydrogenase (GAPB, At1g42970) specific primers were used to quantify mRNA levels. Primers used for RT-PCR of the XI-1 and GAPB are listed here:

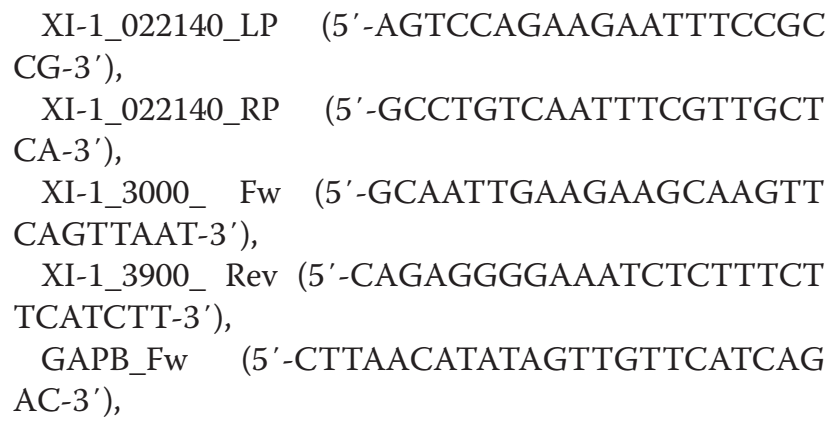

GAPB_Rev (5'-GCGCCTCTTGTCTCTGTTGAC-3'). Sequencing reactions were performed with BigDye Terminator Cycle Sequencing Kit (Applied Biosystems) according to the protocol provided by the manufacturer and analyzed with DNA analyzer ABIPRISM ${ }^{\mathrm{TM}} 3130$ (Applied Biosystems).

\section{Cell area and circularity measurements}

Five-week-old rosette leaves (5th and 6th leaf) were fixed in Carnoy's fixative (ethanol:acetic acid, 3:1), washed with $70 \%$ ethanol and mounted in Hoyer's 
mounting medium (30 g gum arabic, $50 \mathrm{ml}$ distilled water, $200 \mathrm{~g}$ chloral hydrate, $16 . \mathrm{ml}$ glycerol).

Images of pavement and mesophyll cells were captured using differential interference contrast (DIC) microscopy by Olympus BX61 microscope with a 20x or 40x objective. For calculating cell areas the total image area was divided with total cell number per image using Adobe Photoshop 7.0.

To quantify the differences in cell shape, circularity of pavement cells (from abaxial side) was measured using ImageJ software (http://rsb.info.nih.gov/ij/). Cell circularity was calculated according to the formula $4 \pi^{*}$ area/ perimeter $^{2}$ [41]. For measuring circularity, black and white binary images of single pavement cells were used. Binary images were generated using Adobe Photoshop 7.0.

\section{Trichome isolation and analysis}

Intact trichomes from mature leaves were isolated as described by Zhang and Oppenheimer [70]. Toluidine blue stained trichomes were mounted in Mowiol medium (6 g glycerol; $2.4 \mathrm{~g}$ Mowiol 4-88; $6 \mathrm{ml}$ distilled water; $12 \mathrm{ml} 0.2 \mathrm{M}$ Tris buffer $\mathrm{pH}$ 8.5). Images taken with a $4 \mathrm{x}$ or 10x objective of the Olympus BX61 were processed with Adobe Photoshop 7.0. For trichome size analysis, the height of stalks and branches was measured using Image Tool 3.0 (http://ddsdx.uthscsa.edu/dig/ itdesc.html). The number of trichomes with irregular shape was quantified by counting the presence of at least one of the following phenotypes: elongated interbranch zone, unproportionally elongated individual branches, abnormally elongated stalks, sword-shaped trichomes or slightly twisted shape of trichomes.

For the ploidy and sphericity analysis of trichome nuclei, two-week-old soil grown seedlings were fixed in Carnoy's fixative, washed three times with distilled water (3x15 minutes) and stained overnight with $1 \mu \mathrm{g} / \mathrm{ml}$ of Hoechst 33342 (Molecular Probes). Samples were washed three times with water (3x15 minutes) and mounted in Mowiol medium. Hoechst fluorescence was visualized with 100x objective and $405 \mathrm{~nm}$ excitation of laser scanning microscope (Carl Zeiss LSM 510 DUO). Images were quantified using Imaris (Bitplane Scientific Software). Sum of the fluorescence isosurfaces of Hoechst stained nuclei was used for calculation of ploidy levels of wild type and mutant trichomes; at least 50 trichome nuclei per experiment were measured. To calculate total DNA content the fluorescence of trichome nuclei was calibrated using guard cell nuclei, which are considered to be strictly diploid. In mature wild type trichome the total DNA content is $32 \mathrm{C}$, equal with the four rounds of endoreduplication.

Sphericity of trichome nuclei was calculated using fluorescence isosurfaces of Hoechst stained trichome nuclei. Sphericity $(\Psi)$ of a nucleus is the ratio of the surface area of a sphere (with the same volume as the given nucleus) to the surface area of the nucleus [71].

To perform correlation analysis, sphericity of trichome nuclei was measured and the overall trichome phenotype was evaluated. Trichomes with normal phenotype (equal to wild type) and mutant phenotype were arbitrarily assigned values of 0 and 1 , respectively. The phenotype was considered mutant if the trichome exhibited any of the following features: elongated interbranch zone, irregular branch length, abnormally elongated stalk and sword-shaped trichome.

\section{Analysis of fertility}

For floral organ measurements inflorescences of mutant and wild type plants were dissected using double-sided tape, fine needle (G27) and tweezers. Images were captured using stereomicroscope (Zeiss SteREO Discovery V8) and measurements were done using ImageJ software. Fertility was evaluated measuring the length of siliques, counting the number of siliques and the number of developing seeds in siliques.

\section{Alexander's staining of pollens}

To stain mature pollen grains, flowers were collected from adult plants and stored in 10\% ethanol for at least 2 hours at room temperature. Dehisced anthers were mounted into a drop of Alexander's stain $(10 \mathrm{ml}$ of $95 \%$ ethanol, $10 \mathrm{mg}$ Malachite green $(1 \mathrm{ml}$ of $1 \%$ solution in $95 \%$ alcohol), $50 \mathrm{ml}$ of distilled water, $25 \mathrm{ml}$ of glycerol, 5 $\mathrm{g}$ of phenol, $5 \mathrm{~g}$ of chloral hydrate $50 \mathrm{mg}$ of acid fuchsin ( $5 \mathrm{ml}$ of $1 \%$ solution in water), $5 \mathrm{mg}$ of Orange $\mathrm{G}(0.5 \mathrm{ml}$ of $1 \%$ solution in water) and $2 \mathrm{ml}$ of acetic acid) [72]. A coverslip was placed on the anthers and the slides were incubated overnight at room temperature. Images were taken with a digital camera (Olympus DP70) installed on Olympus BX61 microscope with a 20x objective.

\section{Aniline blue staining of pollen tubes}

For pollen tube staining, pistils were opened longitudinally $12 \mathrm{~h}$ after pollination and staining was performed as described by Pagnussat et al. [73]. The pistils were fixed overnight in Carnoy's fixative, cleared in 10\% chloral hydrate at $65{ }^{\circ} \mathrm{C}$ for 5 minutes, washed with water, and softened with $1 \mathrm{M} \mathrm{NaOH}$ at room temperature, washed with $0.1 \mathrm{M} \mathrm{K}_{2} \mathrm{HPO}_{4}$ buffer (pH 10) and stained with $0,1 \%$ decolorized aniline blue (in $0.1 \mathrm{M} \mathrm{K}_{2} \mathrm{HPO}_{4}$ buffer) for 3 hours. Finally pistils were washed briefly with 0.1 $\mathrm{M} \mathrm{K}_{2} \mathrm{HPO}_{4}$ buffer, mounted on a microscope slide using a drop of $80 \%$ glycerol. Aniline blue fluorescence was visualized with $10 \mathrm{x}$ or $20 \mathrm{x}$ objective of laser scanning microscope (Carl Zeiss LSM 510 DUO). 


\section{SEM analysis of siliques and pistils}

Siliques, flowers and flower buds were dissected on double-sided tape using fine needle (27 G) and tweezers. Images were captured with Hitachi TM-1000 tabletop scanning electron microscope.

\section{Statistical analysis}

Statistical analysis was performed with Microsoft Excel and GraphPad InStat software (GraphPad Software Inc., La Jolla, CA). All data are expressed as mean \pm standard deviation (SD). Datasets were first tested for normality using the Kolmogorov-Smirnov test, and an appropriate statistical test was chosen (indicated in Figure legends and Additional files). For all tests, two-sided p-values were calculated. Pearson's correlation coefficient was calculated to determine relationship between the shape of trichomes and sphericity of their nuclei (Additional file 10).

\section{Additional files}

Additional file 1: A schematic diagram of $X I-1, X I-2$, and $X I-K$ genes with the positions of the T-DNA insertions. Black boxes represent exons, black lines introns, and gray boxes represent 5' and 3' untranslated regions. Above the corresponding T-DNA insertion sites are shown.

Additional file 2: Data for Figure 2B: size of the five-week-old rosette leaves (from 5 th to $10 \mathrm{th}, \mathrm{mm}$ ).

Additional file 3: Data for Figure 2C: cell areas $\left(\mu \mathrm{m}^{2}\right)$ of pavement and mesophyll cells of five-week-old rosette leaves.

Additional file 4: Data for Figure 2E: circularity of pavement cells on the leaf abaxial epidermis.

Additional file 5: Shoot size of six-week-old plants. Wild type plants are on the left and $x i-1 / x i-2 / x i-k$ plants are on the right. Both bolt formation as well as onset of flowering of $x i-1 / x i-2 / x i-k$ plants delays significantly (two weeks).

Additional file 6: Data for supplementing Additional file 5: inflorescence shoot height $(\mathrm{cm})$.

Additional file 7: Data for Figure 3A: lenght of trichome stalk and branches $(\mu \mathrm{m})$.

Additional file 8: Data for Figure 3B: length ratios of the trichome stalk and branches.

Additional file 9: Data for Figure 5B: sphericity of trichome nuclei.

Additional file 10: Data for figure 5B: spherisity data and correlation between the sphericity of the trichome nucleus and the trichome shape.

Additional file 11: Data for Figure 7: number of siliques per main stem.

Additional file 12: Data for Figures 6 and 7: length of the siliques $(\mathrm{mm})$ and number of seeds per silique.

Additional file 13: Pollen viability assessed by Alexander's staining method. Pollen viability (purple-colored cytoplasm of pollen grains) is similar both in wild type (WT) as well as in all double and triple mutant plants. Bar $=100 \mu \mathrm{m}$.

Additional file 14: Development of pollen tubes in self-pollinated pistils. Shortly after the onset of flowering first three flowers on the primary shoot were analyzed. A-C) Aniline blue staining of wild type (WT) pistils. D-F) Aniline blue staining of $x i-1 / x i-2 / x i-k$ pistils. In $x i-1 / x i-2 / x i-k$, pollen grains were not attached to the stigmas and pollen tubes were not formed. Pg - pollen grains; Pt - pollen tubes. Bar $=100 \mu \mathrm{m}$.

Additional file 15: Data for Figure 9: size of floral organs (mm), length of the peduncles, sepals, petals and buds.

\section{Acknowledgements}

We thank the Arabidopsis Biological Resource Center and the Salk Institute Genomic Analysis Laboratory for providing T-DNA insertion mutants. We thank Birger Ilau, Kristiina Talts and Illar Pata for carefully reading the manuscript, Signe Nõu for taking care of plants, Olga Volobujeva and Enn Mellikov for providing tabletop SEM for trichome and flower analysis, and Luis Vidali (Worcester Polytechnic Institute) for the assistance with circularity analysis, and Lisa Harper (University of California, Berkeley) for correcting the language of the manuscript. This research was supported by grant number 8604 from the Estonian Science Foundation and by the EU through the European Regional Development Fund (Center of Excellence ENVIRON).

\section{Author details}

'Department of Gene Technology, Tallinn University of Technology, Akadeemia tee 15, 12618 Tallinn, Estonia. ${ }^{2}$ Nachhaltigkeits-Projekte, Alte Str. 13, 79249 Merzhausen, Germany.

\section{Authors' contributions}

EO participated in most of the experimental analyses and wrote the draft of the manuscript. KT did part of the sequencing, RT-PCR, helped with SEM and DIC images and made cell area measurements. PP made statistical analysis of the data. KJ made $x i-1 / x i-k$ double mutant line and participated in root hair measurements. $\mathrm{CH}$ shared T-DNA line of $x i-2$ and participated in creating double mutant $x i-2 / x i-k$ line. ET participated in design of the study and in analysis of the data and helped to draft the manuscript. HP made images and analysis of trichome nuclei; made images of root hairs; participated in design of the study and in analysis of the data and helped to draft the manuscript. All authors read and approved the final manuscript.

Received: 22 August 2011 Accepted: 28 May 2012

Published: 6 June 2012

\section{References}

1. Bögre L, Magyar Z, López-Juez E: New clues to organ size control in plants. Genome Biol 2008, 9:226.

2. Mathur J, Hülskamp M: Microtubules and microfilaments in cell morphogenesis in higher plants. Curr Biol 2002, 12:R669-R676.

3. Guimil S, Dunand C: Cell growth and differentiation in Arabidopsis epidermal cells. J Exp Bot 2007, 58:3829-3840.

4. Pollard TD, Cooper JA: Actin, a central player in cell shape and movement. Science 2009, 326:1208-1212.

5. Reddy AS, Day IS: Analysis of the myosins encoded in the recently completed Arabidopsis thaliana genome sequence. Genome Biol 2001, 2: RESEARCH0024.1- RESEARCH0024.17.

6. Foth BJ, Goedecke MC, Soldati D: New insights into myosin evolution and classification. Proc Natl Acad Sci U S A 2006, 103:3681-3686.

7. Avisar D, Prokhnevsky Al, Makarova KS, Koonin EV, Dolja W: Myosin XI-K Is Required for Rapid Trafficking of Golgi Stacks, Peroxisomes, and Mitochondria in Leaf Cells of Nicotiana benthamiana. Plant Physiol 2008, 146:1098-1108.

8. Peremyslov W, Mockler TC, Filichkin SA, Fox SE, Jaiswal P, Makarova KS, Koonin EV, Dolja W: Expression, splicing, and evolution of the myosin gene family in plants. Plant Physiol 2011, 155:1191-1204

9. Reichelt S, Knight AE, Hodge TP, Baluska F, Samaj J, Volkmann D, Kendrick-Jones J: Characterization of the unconventional myosin VIII in plant cells and its localization at the post-cytokinetic cell wall. Plant $J$ 1999, 19:555-567.

10. Baluska F, Cvrckova F, Kendrick-Jones J, Volkmann D: Sink Plasmodesmata as Gateways for Phloem Unloading. Myosin VIII and Calreticulin as Molecular Determinants of Sink Strength? Plant Physiol 2001, 126:39-46.

11. Avisar D, Prokhnevsky Al, Dolja W: Class VIII myosins are required for plasmodesmatal localization of a closterovirus $\mathrm{Hsp70}$ homolog. J Virol 2008, 82:2836-2843

12. Golomb L, Abu-Abied M, Belausov E, Sadot E: Different subcellular localizations and functions of Arabidopsis myosin VIII. BMC Plant Biol 2008, 8:3.

13. Sattarzadeh A, Franzen R, Schmelzer E: The Arabidopsis class VIII myosin ATM2 is involved in endocytosis. Cell Motil Cytoskeleton 2008, 65:457-468

14. Lee Y-RJ, Liu B: Cytoskeletal Motors in Arabidopsis. Sixty-One Kinesins and Seventeen Myosins. Plant Physiol 2004, 136:3877-3883. 
15. Hashimoto K, Igarashi H, Mano S, Nishimura M, Shimmen T, Yokota E: Peroxisomal localization of a myosin $\mathrm{XI}$ isoform in Arabidopsis thaliana. Plant Cell Physiol 2005, 46:782-789.

16. Li J-F, Nebenführ A: Organelle Targeting of Myosin XI Is Mediated by Two Globular Tail Subdomains with Separate Cargo Binding Sites. J Biol Chem 2007, 282:20593-20602.

17. Reisen D, Hanson MR: Association of six YFP-myosin XI-tail fusions with mobile plant cell organelles. BMC Plant Biol 2007, 7:6.

18. Avisar D, Abu-Abied M, Belausov E, Sadot E, Hawes C, Sparkes IA: A Comparative Study of the Involvement of 17 Arabidopsis Myosin Family Members on the Motility of Golgi and Other Organelles. Plant Physiol 2009, 150:700-709.

19. Peremyslov W, Prokhnevsky Al, Avisar D, Dolja W: Two Class XI Myosins Function in Organelle Trafficking and Root Hair Development in Arabidopsis. Plant Physiol 2008, 146:1109-1116.

20. Prokhnevsky Al, Peremyslov W, Dolja W: Overlapping functions of the four class XI myosins in Arabidopsis growth, root hair elongation, and organelle motility. Proc Natl Acad Sci U S A 2008, 105:19744-19749.

21. Sparkes IA, Teanby NA, Hawes C: Truncated myosin XI tail fusions inhibit peroxisome, Golgi, and mitochondrial movement in tobacco leaf epidermal cells: a genetic tool for the next generation. J Exp Bot 2008, 59:2499-2512

22. Peremyslov W, Prokhnevsky Al, Dolja W: Class XI myosins are required for development, cell expansion, and F-Actin organization in Arabidopsis. Plant Cell 2010, 22:1883-1897.

23. Ueda H, Yokota E, Kutsuna N, Shimada T, Tamura K, Shimmen T, Hasezawa S, Dolja W, Hara-Nishimura I: Myosin-dependent endoplasmic reticulum motility and F-actin organization in plant cells. Proc Natl Acad Sci U S A 2010, 107:6894-6899.

24. Ojangu E-L, Järve K, Paves $H$, Truve E: Arabidopsis thaliana myosin XIK is involved in root hair as well as trichome morphogenesis on stems and leaves. Protoplasma 2007, 230:193-202.

25. Mathur J: The ARP2/3 complex: giving plant cells a leading edge. Bioessays 2005, 27:377-387

26. Smith LG, Oppenheimer DG: Spatial control of cell expansion by the plant cytoskeleton. Annu Rev Cell Dev Biol 2005, 21:271-295.

27. Szymanski DB: Breaking the WAVE complex: the point of Arabidopsis trichomes. Curr Opin Plant Biol 2005, 8:103-112.

28. Mathur J: Local interactions shape plant cells. Curr Opin Cell Biol 2006 , 18:40-46.

29. Li S, Blanchoin L, Yang Z, Lord EM: The putative Arabidopsis arp2/3 complex controls leaf cell morphogenesis. Plant Physio/ 2003, 132:2034-2044.

30. Mathur J, Mathur N, Kernebeck B, Hülskamp M: Mutations in actin-related proteins 2 and 3 affect cell shape development in Arabidopsis. Plant Cell 2003, 15:1632-1645.

31. Basu D, El-Assal SE-D, Le J, Mallery EL, Szymanski DB: Interchangeable functions of Arabidopsis PIROGI and the human WAVE complex subunit SRA1 during leaf epidermal development. Development 2004, 131:4345-4355.

32. Basu D, Le J, El-Essal SE-D, Huang S, Zhang C, Mallery EL, Koliantz G, Staiger CJ, Szymanski DB: DISTORTED3/SCAR2 is a putative arabidopsis WAVE complex subunit that activates the Arp $2 / 3$ complex and is required for epidermal morphogenesis. Plant Cell 2005, 17:502-524.

33. Zhang X, Dyachok J, Krishnakumar S, Smith LG, Oppenheimer DG: IRREGULAR TRICHOME BRANCH1 in Arabidopsis encodes a plant homolog of the actin-related protein $2 / 3$ complex activator Scar/WAVE that regulates actin and microtubule organization. Plant Cell 2005, 17:2314-2326.

34. Zhang C, Mallery EL, Schlueter J, Huang S, Fan Y, Brankle S, Staiger CJ, Szymanski DB: Arabidopsis SCARs function interchangeably to meet actin-related protein 2/3 activation thresholds during morphogenesis. Plant Cell 2008, 20:995-1011.

35. Szymanski DB, Marks MD, Wick SM: Organized F-actin is essential for normal trichome morphogenesis in Arabidopsis. Plant Cell 1999, 11:2331-2347.

36. Le J, El-Assal SE-D, Basu D, Saad ME, Szymanski DB: Requirements for Arabidopsis ATARP2 and ATARP3 during epidermal development. Curr Biol 2003, 13:1341-1347.

37. El-Assal SE-D, Le J, Basu D, Mallery EL, Szymanski DB: Arabidopsis GNARLED encodes a NAP125 homolog that positively regulates ARP2/3. Curr Biol 2004, 14:1405-1409.
38. Zimmermann I, Saedler R, Mutondo M, Hulskamp M: The Arabidopsis GNARLED gene encodes the NAP125 homolog and controls several actin-based cell shape changes. Mol Genet Genomics 2004, 272:290-296.

39. Saedler R, Jakoby M, Marin B, Galiana-Jaime E, Hülskamp M: The cell morphogenesis gene SPIRRIG in Arabidopsis encodes a WD/BEACH domain protein. Plant J 2009, 59:612-621.

40. Le J, Mallery EL, Zhang C, Brankle S, Szymanski DB: Arabidopsis BRICK1/ HSPC300 Is an Essential WAVE-Complex Subunit that Selectively Stabilizes the Arp2/3 Activator SCAR2. Curr Biol 2006, 16:895-901.

41. Vidali L, Augustine RC, Kleinman KP, Bezanilla M: Profilin is essential for tip growth in the moss Physcomitrella patens. Plant Cell 2007, 19:3705-3722.

42. Sorek N, Gutman O, Bar E, Abu-Abied M, Feng X, Running MP, Lewinsohn E, Ori N, Sadot E, Henis Yl, Yalovsky S: Differential Effects of Prenylation and S-Acylation on Type I and II ROPS Membrane Interaction and Function. Plant Physiol 2011, 155:706-720

43. Szymanski DB, Jilk RA, Pollock SM, Marks MD: Control of GL2 expression in Arabidopsis leaves and trichomes. Development 1998, 125:1161-1171.

44. Hülskamp M, Misŕa S, Jürgens G: Genetic dissection of trichome cell development in Arabidopsis. Cell 1994, 76:555-566.

45. Szymanski DB, Marks MD: GLABROUS1 overexpression and TRIPTYCHON alter the cell cycle and trichome cell fate in Arabidopsis. Plant Cell 1998, 10:2047-2062

46. Hülskamp M, Schnittger A, Folkers U: Pattern formation and cell differentiation: trichomes in Arabidopsis as a genetic model system. Int Rev Cytol 1999, 186:147-178.

47. Schnittger A, Hülskamp M: Trichome morphogenesis: a cell-cycle perspective. Philos Trans R Soc Lond B Biol Sci 2002, 357:823-826.

48. Marcotrigiano M: A role for leaf epidermis in the control of leaf size and the rate and extent of mesophyll cell division. Am J Bot 2010, 97:224-233.

49. Savaldi-Goldstein S, Peto C, Chory J: The epidermis both drives and restricts plant shoot growth. Nature 2007, 446:199-202.

50. Savaldi-Goldstein S, Chory J: Growth coordination and the shoot epidermis. Curr Opin Plant Biol 2008, 11:42-48.

51. Mathur J, Spielhofer P, Kost B, Chua N: The actin cytoskeleton is required to elaborate and maintain spatial patterning during trichome cell morphogenesis in Arabidopsis thaliana. Development 1999 126:5559-5568

52. Schwab B, Mathur J, Saedler R, Schwarz H, Frey B, Scheidegger C, Hülskamp $M$ : Regulation of cell expansion by the DISTORTED genes in Arabidopsis thaliana: actin controls the spatial organization of microtubules. $\mathrm{Mol}$ Genet Genomics 2003, 269:350-360.

53. Dittmer TA, Richards EJ: Role of LINC proteins in plant nuclear morphology. Plant Signal Behav 2008, 3:485-487

54. Seagull RW, Falconer MM, Weerdenburg CA: Microfilaments: dynamic arrays in higher plant cells. J Cell Biol 1987, 104:995-1004.

55. Meagher RB, McKinney EC, Kandasamy MK: Isovariant Dynamics Expand and Buffer the Responses of Complex Systems: The Diverse Plant Actin Gene Family. Plant Cell 1999, 11:995-1006.

56. Yu M, Yuan M, Ren H: Visualization of actin cytoskeletal dynamics during the cell cycle in tobacco (Nicotiana tabacum L. cv Bright Yellow) cells. Biol Cell 2006, 98:295-306.

57. Walter N, Holweg CL: Head-neck domain of Arabidopsis myosin XI, MYA2, fused with GFP produces F-actin patterns that coincide with fast organelle streaming in different plant cells. BMC Plant Biol 2008, 8:74

58. Harries PA, Pan A, Quatrano RS: Actin-related protein2/3 complex component ARPC1 is required for proper cell morphogenesis and polarized cell growth in Physcomitrella patens. Plant Cell 2005, 17:2327-2339

59. Qian P, Hou S, Guo G: Molecular mechanisms controlling pavement cell shape in Arabidopsis leaves. Plant Cell Rep 2009, 28:1147-1157.

60. Kandasamy MK, Thorsness MK, Rundle SJ, Goldberg ML, Nasrallah JB, Nasrallah ME: Ablation of Papillar Cell Function in Brassica Flowers Results in the Loss of Stigma Receptivity to Pollination. Plant Cell 1993, 5:263-275.

61. Alvarez-Buylla ER, Benítez M, Corvera-Poiré A, Cador AC, de Folter S, de Buen AG, Garay-Arroyo A, García-Ponce B, Jaimes-Miranda F, Pérez-Ruiz RV, Piñeyro-Nelson A, Sánchez-Corrales YE: Flower Development. The Arabidopsis Book 2010, 8:e0127. doi10.1199/tab.0127.

62. Edlund AF, Swanson R, Preuss D: Pollen and stigma structure and function: the role of diversity in pollination. Plant Cell 2004, 16(Suppl): S84-S97. 
63. Nasrallah JB, Stein JC, Kandasamy MK, Nasrallah ME: Signaling the arrest of pollen tube development in self-incompatible plants. Science 1994, 266:1505-1508.

64. Nemhauser JL, Feldman LJ, Zambryski PC: Auxin and ETTIN in Arabidopsis gynoecium morphogenesis. Development 2000, 127:3877-3888.

65. Maisch J, Nick P: Actin Is Involved in Auxin-Dependent Patterning. Plant Physiol 2007, 143:1695-1704.

66. Perrot-Rechenmann C: Cellular responses to auxin: division versus expansion. Cold Spring Harb Perspect Biol 2010, 2:a001446.

67. Iwano M, Shiba H, Matoba K, Miwa T, Funato M, Entani T, Nakayama P, Shimosato H, Takaoka A, Isogai A, Takayama S: Actin Dynamics in Papilla Cells of Brassica rapa during Self- and Cross-Pollination. Plant Physiol 2007, 144:72-81.

68. Alonso JM, Stepanova AN, Leisse TJ, Kim CJ, Chen H, Shinn P, Stevenson DK, Zimmerman J, Barajas P, Cheuk R, Gadrinab C, Heller C, Jeske A, Koesema E, Meyers CC, Parker H, Prednis L, Ansari Y, Choy N, Deen H, Geralt M, Hazari N, Hom E, Karnes M, Mulholland C, Ndubaku R, Schmidt I, Guzman P, Aguilar-Henonin L, Schmid M, Weigel D, Carter DE, Marchand T, Risseeuw E, Brogden D, Zeko A, Crosby WL, Berry CC, Ecker JR: Genomewide insertional mutagenesis of Arabidopsis thaliana. Science 2003, 301:653-657.

69. Oñate-Sánchez L, Vicente-Carbajosa J: DNA-free RNA isolation protocols for Arabidopsis thaliana, including seeds and siliques. BMC Res Notes 2008, 1:93.

70. Zhang $X$, Oppenheimer DG: A simple and efficient method for isolating trichomes for downstream analyses. Plant Cell Physiol 2004, 45:221-224.

71. Wadell H: Volume, Shape, and Roundness of Quartz Particles. J Geol 1935, 43:250-280.

72. Alexander MP: Differential staining of aborted and nonaborted pollen. Stain Technol 1969, 44:117-122.

73. Pagnussat GC, Yu H-J, Sundaresan V: Cell-Fate Switch of Synergid to Egg Cell in Arabidopsis eostre Mutant Embryo Sacs Arises from Misexpression of the BEL1-Like Homeodomain Gene BLH1. Plant Cell 2007, 19:3578-3592.

doi:10.1186/1471-2229-12-81

Cite this article as: Ojangu et al.: Myosins $\mathrm{XI}-\mathrm{K}, \mathrm{XI}-1$, and $\mathrm{XI}-2$ are required for development of pavement cells, trichomes, and stigmatic papillae in Arabidopsis. BMC Plant Biology 2012 12:81.

\section{Submit your next manuscript to BioMed Central and take full advantage of:}

- Convenient online submission

- Thorough peer review

- No space constraints or color figure charges

- Immediate publication on acceptance

- Inclusion in PubMed, CAS, Scopus and Google Scholar

- Research which is freely available for redistribution 